\title{
Transfer of Dietary Coenzyme Q10 into the Egg Yolk of Laying Hens
}

\author{
Hiroshi Kamisoyama, Kazuhisa Honda, Kanako Kitaguchi and Shin Hasegawa \\ Graduate School of Agricultural Science, Kobe University, Kobe 657-8501, Japan
}

\begin{abstract}
Coenzyme Q10 (CoQ10), a potent lipophilic antioxidant, is a naturally occurring compound with a ubiquitous distribution in nature, and CoQ10 is used as a dietary supplement to combat aging. There is evidence that lipid soluble nutrients can be transferred into the egg yolk from the feed in laying hens. It is therefore possible that feeding CoQ10 to laying hens increases the content of CoQ10 in the egg yolk. In the present study, we investigated the effect of dietary CoQ 10 on its content in the egg yolk of laying hens. Twenty 30 weeks-old Boris Brown hens were assigned based on egg production rate and egg weight to 2 groups (10 birds in each group) and fed a diet containing CoQ10 at 0 or $0.8 \%$ for 28 days. Dietary CoQ10 did not affect average egg production rate, feed efficiency, egg weight, and egg yolk weight. CoQ10 content in the egg yolk was increased significantly at 7, 14, 21 and 28 days of the experimental period. Hepatic CoQ10 content and plasma very low density lipoprotein y (VLDLy) CoQ10 concentration in $0.8 \%$ group were increased significantly compared with those in $0 \%$ group. Dietary CoQ10 significantly decreased cholesterol concentration in the egg yolk at $21^{\text {st }}$ and $28^{\text {th }}$ day of the experimental period. These findings suggest that, in CoQ10-fed laying hens, the increase of hepatic CoQ10 elevates the plasma VLDLy CoQ10 concentration, which in turn results in a high CoQ10 content in the egg yolk of laying hens.
\end{abstract}

Key words: cholesterol, coenzyme Q10, egg, ubiquinone

J. Poult. Sci., 47: 28-33, 2010

\section{Introduction}

Coenzyme Q $(\mathrm{CoQ})$, a potent fat-soluble antioxidant, is a naturally occurring compound with a ubiquitous distribution in nature. Based on the isoprenoid moiety, the presence of various CoQ homologues has been confirmed (Albano et al., 2002; Hihi et al., 2003). CoQ10 has a polyisoprene chain containing 10 isoprene units (Fig 1). $\mathrm{CoQ} 10$ is predominant in humans and birds, whereas CoQ 9 is predominant in rats and mice (Battino et al., 1990; Dallner and Sindelar, 2000; Albano et al., 2002).

In humans, oral supplementation with CoQ10 has been shown to improve the health status in several diseases including cardiovascular diseases (Langsjoen and Langsjoen, 1999; Belardinelli et al., 2006) and pediatric cardiomyophathy Parkinson's and Huntington's disease (Kieburtz, 1999; Beal, 2002; Shults et al., 2002; Shults, 2003). In addition, the amount of CoQ10 decreases rapidly after the age of 40 years (Kalén et al., 1989). Therefore, CoQ10 is used as a dietary supplement to combat aging worldwide, and it has become increasingly popular. On the other hand, in chickens, only a few studies have been performed in broiler chickens. For

Received: May 15, 2009, Accepted: June 30, 2009

Released Online Advance Publication: December 10, 2009

Correspondence: Dr. S Hasegawa, Graduate School of Agricultural

Science, Kobe University, Kobe 657-8501, Japan.

(E-mail: hasegawa@kobe-u.ac.jp) example, Geng and colleagues demonstrated that dietary CoQ10 supplementation reduced broiler chickens' susceptibility to ascites, which might be the result of improving hepatic mitochondrial function, some respiratory chainrelated enzymes activities and mitochondrial antioxidative capability (Geng et al., 2004; Geng and Guo, 2005). However, the effects of dietary CoQ10 on laying hens have not yet been examined.

In mammals, the absorption of CoQ10 follows the same process as that of fat-soluble nutrients in the gastrointestinal tract (Bhagavan and Chopra, 2006). Following absorption, CoQ10 is taken up rapidly by the liver where CoQ10 is repackaged into very low density lipoprotein (VLDL) particles and released into circulation (Bhagavan and Chopra, 2006). Kaikkonen et al. (1997) reported that dietary CoQ10 elevates Q10 in VLDL plus low density lipoprotein fraction by $160 \%$. All this evidence suggests that dietary CoQ10 increases plasma VLDL CoQ10 concentration. In laying hens, VLDL particles are synthesized in the liver and released into circulation (Schneider et al., 1990) as well as in mammals. However, this VLDL particle, which has been termed yolk targeted VLDL (VLDLy), contains large amounts of apoVLDL II. Since apoVLDL II is an inhibitor of lipoprotein lipase, most of the VLDLy particles escape lipolysis (Schneider et al., 1990; MacLachlan et al., 1996), thus ensuring the efficient delivery of lipids, protein, fatsoluble vitamins, and other nutrients to the growing 
oocytes. In fact, several fat-soluble nutrients are transferred from the feed to the egg yolk (Chamruspollert and Sell, 1999; Lewis et al., 2000; Grobas et al., 2002; Mattila et al., 2004; Leeson and Caston, 2004; Olson et al., 2008; Saitoh et al., 2001). These findings raise the hypothesis that dietary CoQ10 can transfer to the egg yolk of laying hens.

In mammals, the cholesterol-lowering effect of dietary CoQ has been reported. For example, dietary CoQ10 decreases plasma total cholesterol concentration in diabetic rats (Modi et al., 2006) and patients with recent myocardial infarction (Singh et al., 2003). Krishnaiah and Ramasarma (1970) reported that CoQ9 suppresses hepatic cholesterogenesis and decrease serum cholesterol concentration in rats. In laying hens, egg cholesterol is first biosynthesized in the liver (Andrews et al., 1968) and secreted into the blood in the form of VLDLy (Burley et al., 1984; George et al., 1987; Elkin, 2006). VLDLy is then transported to the ovary (Nimpf and Shneider, 1991; Elkin, 2006). However, the effect of dietary CoQ10 on the content of cholesterol in the egg yolk have not been examined.

In the present study, an experiment was designed to determine the effects of dietary CoQ10 on the contents of CoQ10 and cholesterol in the egg yolk.

\section{Materials and Methods}

\section{Experimental Design}

Twenty 30 weeks-old Boris Brown hens were housed in wired laying cage (one bird per cage) and fed on the commercial feed (Nippon Formula Feed Mfg. Co., Ltd., Kanagawa, Japan) for 1 week before the experiment. The birds were assigned based on egg production rate and egg weight to 2 groups (10 birds in each group). Yeastderived CoQ10 (Kaneka Co., Osaka, Japan), which is permitted as a feed stuff in Japan, was used in this study. In this experiment, pair-feeding was employed to keep the food and CoQ10 intakes the same. The birds were pair fed at $100 \mathrm{~g} /$ day of the commercial feed containing either 0 (as a control) or $0.8 \%$ of CoQ10 during the experimental period. Eggs were collected every day at $12 \mathrm{AM}$ and weighed. Egg yolk weight and the contents of CoQ10 and cholesterol in the egg yolk were measured at 7, 14, 21 and 28 days after the experiment was introduced. At the end of the experiment, hens were sacrificed by decapitation and their blood was collected. Plasma was separated

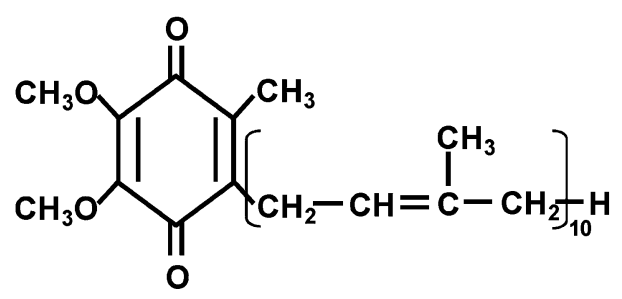

Fig. 1. Structure of coenzyme Q10. immediately by centrifugation at $3,000 \times g$ for $10 \mathrm{~min}$ at $4^{\circ} \mathrm{C}$, frozen by liquid nitrogen and stored at $-80^{\circ} \mathrm{C}$ for CoQ10 analysis. The liver was excised, weighed, frozen immediately by liquid nitrogen, and stored at $-80^{\circ} \mathrm{C}$ for CoQ10 analysis. All experimental procedures followed the guidelines for the care and use of experimental animals at the Rokkodai Campus of Kobe University in Japan.

Preparation of VLDLy

Selective precipitation of the apolipoprotein Bcontaining lipoprotein VLDL from human serum with heparin and $\mathrm{Ca}^{2+}$ has been reported (Cham, 1976). VLDLy particle, which is smaller than VLDL particle, contains apolipoprotein B (Walzem et al., 1999). In the preliminary experiment, we confirmed by electrophoresis that the isolated VLDLy by the method of Cham (1976) contains apoVLDL-II, the VLDLy specific apolipoprotein, as mentioned in the introduction (data not shown). Thus, in the present study, VLDLy was isolated from the frozen plasma by the method of Cham (1976).

\section{CoQ10 Analysis}

CoQ10 concentrations in the liver, VLDLy and the egg yolk were determined by the method of Menke et al. (2000) as follows: CoQ10 was extracted from the liver, VLDLy and the egg yolk by methanol-hexane (2: 3, vol/ vol), reduced by iron chloride and analyzed using HPLC.

\section{Measurement of Cholesterol Contents}

Cholesterol was extracted from the egg yolk by chloroform-methanol (1: 2, vol/vol) and determined enzymatically using a commercial kit (Cholesterol E-test Wako, Wako Pure Chemical Industries, Ltd., Osaka, Japan).

\section{Statically Analysis}

All data were analyzed by Student's $t$-test using the commercial package StatView version 5 (SAS Institute, Cary, North Carolina, USA, 1998)

\section{Results}

Dietary CoQ10 did not affect egg production rate and feed efficiency (Table 1). Egg production rate was calculated as $100 \times$ number of eggs laid/(number of hens $\times$ days). Feed efficiency was calculated as egg weight (g)/ feed intake (g). Dietary CoQ10 did not affect the weights of egg and egg yolk (Table 1). CoQ10 content in the egg yolk was significantly increased already at day 7 (from

Table 1. Effect of dietary coenzyme Q10 on egg production rate, feed efficiency, egg weight and egg yolk weight in laying hens

\begin{tabular}{lrr}
\hline \hline & \multicolumn{1}{c}{$0 \%$} & \multicolumn{1}{c}{$0.8 \%$} \\
\hline${\text { Egg production rate }(\%)^{\mathrm{a}}}$ & $87.14 \pm 0.87$ & $82.86 \pm 2.08$ \\
Feed efficiency & $0.57 \pm 0.02$ & $0.56 \pm 0.02$ \\
Egg weight $(\mathrm{g})$ & $65.09 \pm 1.30$ & $66.35 \pm 1.41$ \\
Egg yolk weight $(\mathrm{g})$ & $15.10 \pm 0.38$ & $15.35 \pm 0.35$ \\
\hline a: $: 100 \times$ number of eggs laid/(number of hens $\times$ days $)$ \\
b: egg weight $(\mathrm{g}) /$ feed intake $(\mathrm{g})$
\end{tabular}


$4.35 \pm 0.44 \mu \mathrm{g} / \mathrm{g}$ egg yolk to $11.61 \pm 1.92 \mu \mathrm{g} / \mathrm{g}$ egg yolk, $P$ $<0.01$ ), and an additional increase was observed during the next 7 days (to $22.46 \pm 2.00 \mu \mathrm{g} / \mathrm{g}$ egg yolk, $P<0.01$ ), and this value was substantially maintained throughout the remainder of the experiment (Fig. 2). Hepatic CoQ10 content (Fig. 3) and VLDLy CoQ10 concentration (Fig. $4)$ of $0.8 \%$ group were increased significantly $(P<0.01)$ compared with those of the $0 \%$ group. These values were more than 5-fold higher than those of the $0 \%$ group. Dietary CoQ10 decreased cholesterol concentration in the egg yolk significantly $(P<0.05)$ at $21^{\text {st }}$ and $28^{\text {th }}$ day of the experiment $(89.66 \pm 2.6 \%$ and $92.95 \pm 3.2 \%$, respectively; Fig. 5). There is no significant difference in the egg production rate between groups $(0 \%$ group, $82.9 \pm 1.2 \%$; $0.8 \%$ group, $80.2 \pm 1.0 \%$, respectively) during day 21 to day 28. All feed was eaten in both groups throughout the experimental period.

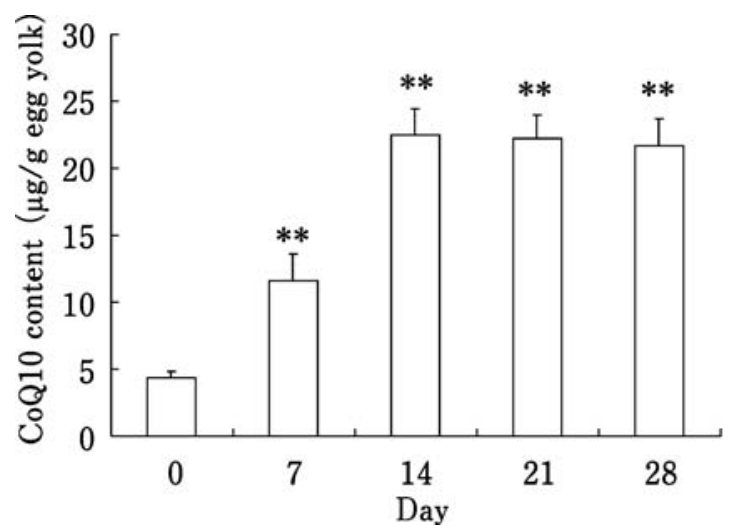

Fig. 2. Effect of dietary coenzyme Q10 on coenzyme Q10 content in the egg yolk. Data represent the mean $\pm \mathrm{SEM}$ of 10 hens per group. **, significant with respect to day $0(P<0.01)$.

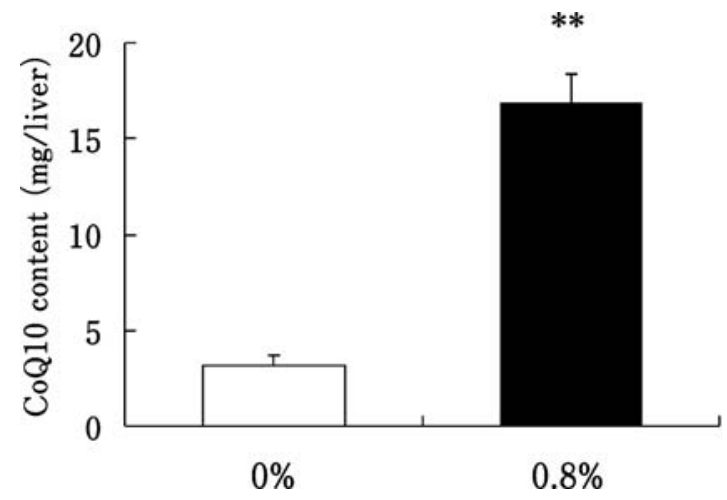

Fig. 3. Effect of dietary coenzyme Q10 on hepatic coenzyme Q10 content. Data represent the mean士 SEM of 10 hens per group. **, significant with respect to $0 \%$ group $(P<0.01)$.

\section{Discussion}

CoQ10 is a ubiquinone present in both animal and plant cellular membranes. Two major functions are attributed to this compound, namely as an electron carrier in the mitochondrial respiratory chain and as a lipid-soluble antioxidant (Kaikkonen et al., 1997; Bhagavan and Chopra, 2006). In addition, other important functions of CoQ10 such as cell signaling and gene expression have been recognized (Ernster and Dallner, 1995; Crane, 2001; Groneberg et al., 2005). Since the amount of CoQ10 decreases rapidly after the age of 40 years in humans (Kalén et al., 1989), CoQ10 is used as a dietary supplement to combat aging worldwide. CoQ10 is ubiquitously found in the diet with daily intakes ranging from 3 to 5 $\mathrm{mg} /$ day (Weber et al., 1997). In the present study, dietary CoQ10 significantly increased CoQ10 content (approximately $0.35 \mathrm{mg}$ CoQ10/egg), suggesting that CoQ10enriched eggs produced in this study could be a good source of CoQ10.

In laying hens, fat-soluble nutrients such as fatty acid (Chamruspollert and Sell, 1999; Lewis et al., 2000), fat soluble vitamins (Grobas et al., 2002; Mattila et al., 2004), cartenoids (Leeson and Caston, 2004; Olson et al., 2008) and isoflavone (Saitoh et al., 2001) are transferred from the feed to the egg yolk. In the present study, dietary CoQ10 significantly increased hepatic CoQ10 content, plasma VLDLy CoQ10 concentration, and CoQ10 content in the egg yolk. In mammals, there is evidence that dietary CoQ10 is repackaged into VLDL particles and released into circulation (Bhagavan and Chopra, 2006). In laying hens, most of the VLDLy particles which is assembled in the liver is transported into the egg yolk (Nimpf and Shneider, 1991). These findings and our results suggest that, in CoQ10-fed laying hens, the increase of hepatic CoQ10 elevates the plasma VLDLy CoQ10 concentration, which in turn results in a high CoQ10

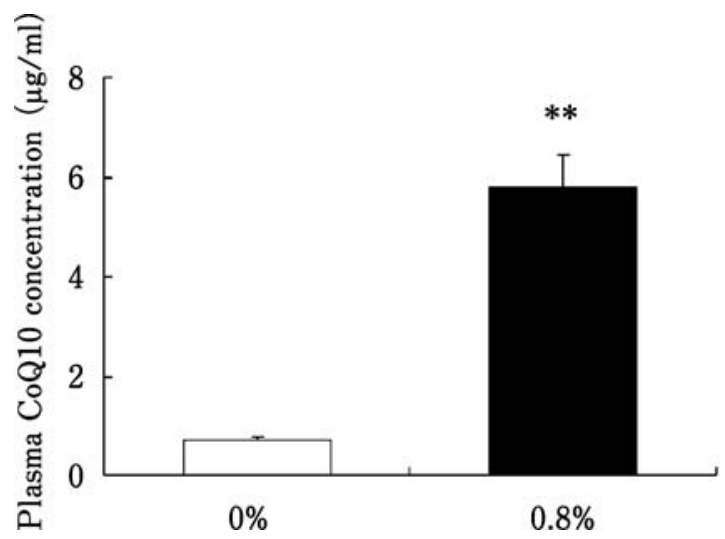

Fig. 4. Effect of dietary coenzyme Q10 on plasma very low density lipoprotein y coenzyme Q10 concentration. Data represent the mean \pm SEM of 10 hens per group. **, significant with respect to $0 \%$ group $(P<0.01)$. 


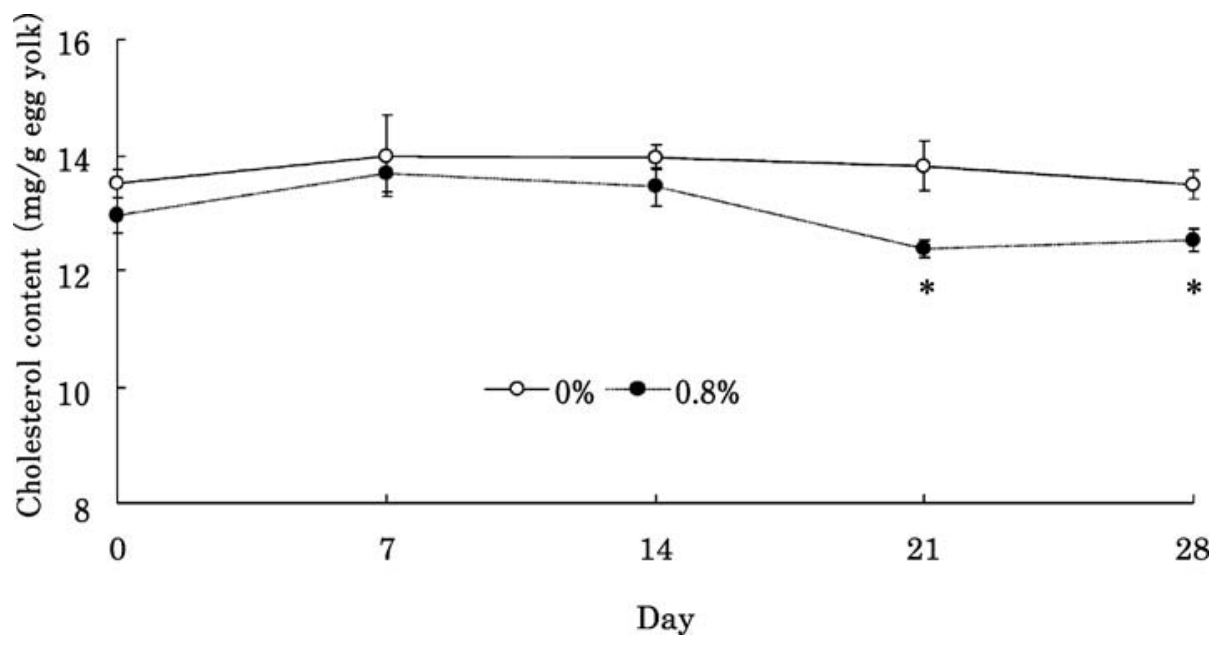

Fig. 5. Effect of dietary coenzyme Q10 on cholesterol content in the egg yolk. Data represent the mean \pm SEM of 10 hens per group. *, significant with respect to $0 \%$ group $(P<0.05)$.

content in the egg yolk.

From a nutritional standpoint, eggs are an excellent source of high-quality protein, mono- and polyunsaturated fatty acids, several minerals, and numerous fat- and water-soluble vitamins (Cook and Briggs, 1977). However, it is recommended that people should limit the consumption of eggs because of their high cholesterol (208 mg/egg) content (Kritchevsky and Kritchevsky, 2000). Therefore, research efforts directed toward reducing egg cholesterol content have centered on alteration of the laying hens' diet with various pharmacological agents and natural products. For example, atorvastatin significantly decreases the content of cholesterol in the egg yolk (Elkins et al., 2003). However, in this study, significant amounts of atorvastatin accumulated in the egg yolk, suggesting that this pharmacological agent can not be a candidate for a feed additive. On the other hand, dietary natural products have resulted in only slight reductions in avian egg cholesterol content (Elkin, 2006). In addition, the effects of several natural products on the egg cholesterol content are conflicting (Hargis et al., 1991; Oh et al., 1991; Scheideler and Froning, 1996). In the present study, we found that natural product CoQ10 significantly decreases the content of cholesterol in the egg yolk of laying hens (90-93\% of control, Fig 5). In addition, evidence from human clinical trials indicates that the upper level for supplements for CoQ10 is $1,200 \mathrm{mg} /$ day in humans (Hathcock and Shao, 2006), suggesting that CoQ10enriched egg, which contains approximately $0.35 \mathrm{mg}$ CoQ $10 /$ egg, has no adverse effects on humans. These findings suggest that CoQ10 is a promising candidate for a feed stuff to decrease the content of cholesterol in the egg yolk.

In laying hens, cholesterol is primarily biosynthesized in the liver and incorporated into VLDLy, which is secreted into the bloodstream and subsequently taken up by growing oocytes (Elkin, 2006). There is evidence that 3- hydroxy- 3 -methylglutaryl coenzyme A reductase (HMGR: a rate-limiting enzyme of cholesterol synthetic pathway) inhibitors are effective egg cholesterol-lowering agents via lowered VLDL cholesterol concentration when orally administered to laying hens (Elkin and Rogler, 1990; Elkin et al., 1999, 2003). In rats, there is evidence that dietary CoQ9 suppresses HMGR activity (Omkumar et al., 1992) and hepatic cholesterogenesis (Krishnaiah and Ramasarma, 1970). It is therefore possible that dietary CoQ10 decreases cholesterol content in the egg yolk by the suppression of hepatic cholesterogenesis. Further study is needed to clarify this point.

In this study, we investigated the effects of dietary CoQ 10 on the egg production and the egg qualities of laying hens. The egg production rate, feed efficiency, egg weight, and egg yolk weight were not influenced by CoQ10 supplementation. Dietary CoQ10 significantly increased the content of CoQ10 and significantly decreased the content of cholesterol in the egg yolk. In addition, dietary CoQ10 significantly increased hepatic CoQ10 content and plasma VLDLy CoQ10 concentration. These findings clearly demonstrate that natural antioxidant CoQ10 can be transferred into the egg yolk from the feed.

\section{Acknowledgments}

This work was supported by a Grant-in-Aid for Scientific Research from the Ministry of Education, Culture, Sports, Science, and Technology of Japan.

\section{References}

Albano CB, Muralikrishnan D and Ebadi M. Distribution of coenzyme $\mathrm{Q}$ homologues in brain. Neurochemical Research, 27: 359-368. 2002.

Andrews JW Jr, Wagstaff RK and Edwards HM. Cholesterol metabolism in the laying fowl. American Journal of Physiology, 214: 1078-1083. 1968. 
Battino M, Ferri E, Gorini A, Federico Villa R, Rodriguez Huertas JF, Fiorella P, Genova ML, Lenaz G, Marchetti M. Natural distribution and occurrence of coenzyme Q homologues. Membrane Biochemistry, 9: 179-190. 1990.

Beal MF. Coenzyme Q10 as a possible treatment for neurodegenerative diseases. Free Radical Research, 36: 455-460. 2002.

Belardinelli R, Muçaj A, Lacalaprice F, Solenghi M, Seddaiu G, Principi F, Tiano L and Littarru GP. Coenzyme Q10 and exercise training in chronic heart failure. European Heart Journal, 27: 2675-2681. 2006.

Bhagavan HN and Chopra RK. Coenzyme Q10: absorption, tissue uptake, metabolism and pharmacokinetics. Free Radical Research, 40: 445-453. 2006.

Burley RW, Sleigh RW and Shenstone FS. Lipoproteins from the blood and egg yolk of the hen. The transfer of very-lowdensity lipoprotein to egg yolk and possible changes to apoprotein B. European Journal of Biochemistry, 142: 171176. 1984.

Cham BE, Nature of the interaction between low-density lipoproteins and polyanions and metal ions, as exemplified by heparin and $\mathrm{Ca}^{2+}$. Clinical Chemistry, 22: 1812-1816. 1976.

Chamruspollert $\mathbf{M}$ and Sell JL. Transfer of dietary conjugated linoleic acid to egg yolks of chickens. Poultry Science, 78: 1138-1150. 1999.

Cook F and Briggs GM. Nutritive value of eggs. In: Egg Science and Technology, 2nd eds. (Stadelman WJ and Cotterill OJ eds.). pp 92-108. Avi Publishing Company. Westport. 1977.

Crane FL. Biochemical functions of coenzyme Q10. Journal of the American College of Nutrition, 20: 591-598. 2001.

Dallner G and Sindelar PJ. Regulation of ubiquinone metabolism. Free Radical Biology and Medicine, 29: 285-294. 2000.

Elkin RG. Reducing shell egg cholesterol content. I. Overview, genetic approaches, and nutritional strategies. World's Poultry Science Journal, 62: 665-687. 2006.

Elkin RG, Furumoto EJ and Thomas CR. Assessment of egg nutrient compositional changes and residue in eggs, tissues, and excreta following oral administration of atorvastatin to laying hens. Journal of Agricultural and Food Chemistry, 51: 3473-3481. 2003.

Elkin RG and Rogler JC. Reduction of the cholesterol content of eggs by the oral administration of lovastatin to laying hens. Journal of Agricultural and Food Chemistry, 38: 16351641. 1990.

Elkin RG, Yan Z, Zhong Y, Donkin SS, Buhman KK, Story JA, Turek JJ, Porter RE Jr, Anderson M, Homan R and Newton RS. Select 3-hydroxy-3-methylglutaryl-coenzyme A reductase inhibitors vary in their ability to reduce egg yolk cholesterol levels in laying hens through alteration of hepatic cholesterol biosynthesis and plasma VLDL composition. Journal of Nutrition. 129: 1010-1019. 1999.

Ernster L and Dallner G. Biochemical, physiological and medical aspects of ubiquinone function. Biochimica et Biophysica Acta, 1271: 195-204. 1995.

Geng AL, Guo YM and Yang Y. Reduction of ascites mortality in broilers by coenzyme Q10. Poultry Science, 83: 15871593. 2004.

Geng AL and Guo YM. Effects of dietary coenzyme Q10 supplementation on hepatic mitochondrial function and the activities of respiratory chain-related enzymes in ascitic broiler chickens. British Poultry Science, 46: 626-634. 2005.
George R, Barber DL and Schneider WJ. Characterization of the chicken oocyte receptor for low and very low density lipoproteins. Journal of Biological Chemistry, 262: 1683816847. 1987.

Grobas S, Méndez J, Bote CL, Blas CD and Mateos GG. Effect of vitamin $\mathrm{E}$ and $\mathrm{A}$ supplementation on egg yolk alphatocopherol concentration. Poultry Science, 81: 376-381. 2002.

Groneberg DA, Kindermann B, Althammer M, Klapper M, Vormann J, Littarru GP and Döring F. Coenzyme Q10 affects expression of genes involved in cell signalling, metabolism and transport in human $\mathrm{CaCo}-2$ cells. International Journal of Biochemistry and Cell Biology, 37: 1208-1218. 2005.

Hargis PS, Van Elswyk ME and Hargis BM. Dietary modification of yolk lipid with menhaden oil. Poultry Science, 70: 874-883. 1991.

Hathcock JN and Shao A. Risk assessment for coenzyme Q10 (Ubiquinone). Regulatory Toxicology and Pharmacology, 45: 282-288. 2006.

Hihi AK, Kebir H and Hekimi S. Sensitivity of Caenorhabditis elegans clk-1 mutants to ubiquinone side-chain length reveals multiple ubiquinone-dependent processes. Journal of Biological Chemistry, 278: 41013-41018. 2003.

Kaikkonen J, Nyyssönen K, Porkkala-Sarataho E, Poulsen HE, Metsä-Ketelä T, Hayn M, Salonen R and Salonen JT. Effect of oral coenzyme Q10 supplementation on the oxidation resistance of human VLDL/LDL fraction: absorption and antioxidative properties of oil and granule-based preparations. Free Radical Biology and Medicine, 22: 1195-1202. 1997.

Kalén A, Appelkvist EL and Dallner G. Age-related changes in the lipid compositions of rat and human tissues. Lipids, 24: 579-584. 1989.

Kieburtz K. Antiglutamate therapies in Huntington's disease. Journal of Neural Transmission. Supplementum. 55: 97102. 1999.

Krishnaiah KV and Ramasarma T. Regulation of hepatic cholesterolgenesis by ubiquinone. Biochimica et Biophysica Acta, 202: 332-342. 1970.

Kritchevsky SB and Kritchevsky D. Egg consumption and coronary heart disease: An epidemiologic overview. Journal of the American College Nutrition, 19: 549-555. 2000.

Langsjoen PH and Langsjoen AM. Overview of the use of CoQ 10 in cardiovascular disease. Biofactors, 9: 273-284. 1999.

Leeson S and Caston L. Enrichment of eggs with lutein. Poultry Science, 83: 1709-1712. 2004.

Lewis NM, Seburg S and Flanagan NL. Enriched eggs as a source of N-3 polyunsaturated fatty acids for humans. Poultry Science, 79: 971-974. 2000.

MacLachlan I, Steyrer E, Hermetter A, Nimpf J and Schneider WJ. Molecular characterization of quail apolipoprotein very-low-density lipoprotein II: disulphide-bond-mediated dimerization is not essential for inhibition of lipoprotein lipase. Biochemical Journal, 317: 599-604. 1996.

Mattila P, Valaja J, Rossow L, Venäläinen E and Tupasela T. Effect of vitamin D2- and D3-enriched diets on egg vitamin $\mathrm{D}$ content, production, and bird condition during an entire production period. Poultry Science, 83: 433-440. 2004.

Menke T, Niklowitz P, Adam S, Weber M, Schlüter B and Andler W. Simultaneous detection of ubiquinol-10, ubiquinone-10, and tocopherols in human plasma micro- 
samples and macrosamples as a marker of oxidative damage in neonates and infants. Analytical Biochemistry, 282: 209217. 2000 .

Modi K, Santani DD, Goyal RK and Bhatt PA. Effect of coenzyme Q10 on catalase activity and other antioxidant parameters in streptozotocin-induced diabetic rats. Biological Trace Element Research, 109: 25-33. 2006.

Nimpf J and Schneider WJ. Receptor-mediated lipoprotein transport in laying hens. Journal of Nutrition, 121: 1471-1474. 1991.

Oh SY, Ryue J, Hsieh CH and Bell DE. Eggs enriched in $\omega-3$ fatty acids and alterations in lipid concentrations in plasma and lipoproteins and in blood pressure. American Journal of Clinical Nutrition, 54: 689-695. 1991.

Olson JB, Ward NE and Koutsos EA. Lycopene incorporation into egg yolk and effects on laying hen immune function. Poultry Science, 87: 2573-2580. 2008.

Omkumar RV, Gaikwad AS and Ramasarma T. Feedback-type inhibition of activity of 3-hydroxy-3-methylglutaryl coenzyme a reductase by ubiquinone. Biochemical and Biophysical Research Communications, 184: 1280-1287. 1992.

Saitoh S, Sato T, Harada $\mathrm{H}$ and Takita T. Transfer of soy isoflavone into egg yolk of chickens. Bioscience, Biotechnology, and Biochemistry, 65: 2220-2225. 2001.
Scheideler SE and Froning GW. The combined influence of dietary flaxseed variety, level, form, and storage conditions on egg production and composition among vitamin Esupplemented hens. Poultry Science, 75: 1221-1226. 1996.

Schneider WJ, Carroll R, Severson DL and Nimpf J. Apolipoprotein VLDL-II inhibits lipolysis of triglyceriderich lipoproteins in the laying hen. Journal of Lipid Research, 31: 507-513. 1990.

Shults CW, Oakes D, Kieburtz K, Beal MF, Haas R, Plumb S, Juncos JL, Nutt J, Shoulson I, Carter J, Kompoliti K, Perlmutter JS, Reich S, Stern M, Watts RL, Kurlan R, Molho E, Harrison M and Lew M. Effects of coenzyme Q10 in early Parkinson disease: evidence of slowing of the functional decline. Archives of Neurology, 59: 1541-1550. 2002.

Shults CW. Coenzyme Q10 in neurodegenerative diseases. Current Medical Chemistry. 10: 1917-1921. 2003.

Singh RB, Neki NS, Kartikey K, Pella D, Kumar A, Niaz MA and Thakur AS. Effect of coenzyme Q10 on risk of atherosclerosis in patients with recent myocardial infarction. Mollecular and Cellular Biochemistry, 246: 75-82. 2003.

Weber C, Bysted A and Hølmer G. Coenzyme Q10 in the diet--daily intake and relative bioavailability. Molecular Aspects of Medicine, 18: S251-S254. 1997. 